\title{
EFEITO DO CUSTO PERDIDO: A INFLUÊNCIA DO CUSTO PERDIDO NA DECISÃO DE INVESTIMENTO
}

\section{LOSS COST EFFECT: THE LOSS COST INFLUENCE IN THE INVESTMENT DECISION}

\author{
CÉSAR AUGUSTO TIBURCIO SILVA \\ Doutor em Contabilidade pela \\ Universidade de São Paulo \\ Professor Titular do Departamento de Ciências Contábeis da \\ Universidade de Brasília \\ E-mail: cesartiburcio@unb.br
}

\author{
FRANCISCA APARECIDA DE SOUZA \\ Mestranda em Contabilidade pela \\ Universidade de Brasília \\ E-mail: francisca_shell@yahoo.com.br
}

\author{
NAIÁRA TAVARES DOMINGOS \\ Mestranda em Contabilidade pela \\ Universidade de Brasília \\ Email: naiaratavares@gmail.com
}

Resumo

A decisão de continuar ou não um projeto, ou mesmo de iniciar um novo investimento que exige continuamente a alocação de recursos, não deve ser influenciada pelos custos passados, uma vez que estes não sofrerão alterações qualquer que seja a decisão futura. Quando a decisão é afetada por investimentos feitos no passado, manifesta-se o "efeito do custo perdido". No entanto, de acordo com a Moderna Teoria de Finanças, os custos perdidos são totalmente irrelevantes para decisão de eventos futuros. Este trabalho constitui uma pesquisa empírica, realizada por meio de aplicação, de forma aleatória, de questionários a alunos de graduação de uma universidade. Buscou-se verificar se, realmente, os indivíduos não consideram os custos perdidos na tomada de decisão. Foi utilizado o teste estatístico do $\chi^{2}$ para testar a significância da diferença entre as respostas dos alunos aos diferentes cenários trabalhados, reforçando assim, a idéia de que o efeito do custo perdido na decisão de alocação de recursos independe da evidenciação ou não dos valores investidos. De acordo com a pesquisa e tendo em vista suas limitações, a evidenciação do valor do custo perdido não influencia a decisão dos gestores. 0 resultado corrobora estudos anteriores nos quais o efeito do custo perdido foi observado.

Palavras-chave: custo perdido; efeito do custo perdido; investimento; finanças comportamentais.

\begin{abstract}
The decision whether to continue or not a project, or even the initiative of a new investment that requires constant resources allocation, should not be influenced by the past costs once these do not have any changes despite future decisions. When the decision is affected by investments made in the past, the "sunk cost effect" can be seen. However, according to the Modern Financial Theory, the loss costs are totally irrelevant for a future decision event. This study is an empirical research developed through a random usage of questionnaires given to graduate students of a university. It was tried to verify if the individuals really do not take importance to the loss cost when the decision is made. The $\chi^{2}$ statistic test was used to show the significance of the different answers collected from students from different scenario, reinforcing this way, the idea that the loss cost effect on the resources allocation decision is not related to neither the disclosure nor the amount invested. According to the research and considering its limitations, the disclosure of the loss cost amount does not influence management decision. The result confirms previous studies in which the loss cost effect was observed.
\end{abstract}

Key words: sunk cost, sunk cost effect, investment, behavioral finances. 


\section{INTRODUÇÃO}

Diante da escolha entre alternativas de ação, o gestor de uma empresa utiliza os custos relevantes para as decisões não rotineiras. Os custos relevantes correspondem aos custos futuros esperados das alternativas disponíveis. A regra desse processo decisório indica que os custos relevantes devem ser comparados com as receitas futuras esperadas para determinar a melhor opção para a empresa. Nas decisões da empresa, os denominados custos perdidos (sunk cost) não são considerados relevantes. Uma vez que o custo é perdido, o mesmo não tem efeito para decisões futuras e não devem ter um papel em escolhas racionais (MARTINS, 2001).

Os custos perdidos são os custos que já foram incorridos. Considere uma situação de um investimento já realizado de 100 milhões de reais num projeto, sendo necessários mais 50 milhões para finalizar o projeto. Uma nova tecnologia permite fazer um projeto similar por 20 milhões, com as mesmas características do original. A decisão óbvia é abandonar o projeto original, perdendo os 100 milhões investidos originalmente. Nessa situação, esse valor já investido é considerado perdido e não interfere no processo decisório, devendo, por isso, ser desconsiderado na análise.

Outra situação ocorre quando pessoas se sentem obrigadas a ficar no cinema até o final de um filme para não dar a impressão de que perdeu dinheiro com o ingresso. A compra do ingresso representaria um custo perdido e esse comportamento não seria racional.

Entretanto, os tomadores de decisão podem ser economicamente irracionais ou terem incentivos que conduzem a decisões errôneas; nessas situações, é possível que a escolha seja por continuar o projeto original. Segundo Yates e Tan (1995), quando o indivíduo se depara com a necessidade de tomar decisão de alocação de recursos em investimentos, este procura não apresentar desperdícios não apenas para si mesmo. É também importante a opinião de terceiros. Nessas situações, as pessoas procuram evitar a má impressão que o desperdício de recurso possa causar, especialmente quando outras pessoas podem puni-las pelo evento desastroso. A dificuldade de o indivíduo desprender-se de um investimento passado, antes que este traga benefício, é real, considerando a escassez dos recursos. Essa situação foi denominada por Arkes e Ayton (1999) como don't waste rule. Esses autores consideram, por sinal, que a generalização da don't waste rule é manifestada por meio do efeito do custo perdido nos humanos.

A literatura assume que as pessoas usaram no processo de escolha um critério de racionalidade e consistência, em que a regra de desconsiderar os custos perdidos nas decisões não rotineiras seja observada. Entretanto, diversas situações práticas têm demonstrado que isso nem sempre é verdadeiro. O problema de considerar os custos perdidos no processo decisório recebem a denominação de efeito do custo perdido ou falácia do custo perdido ou sunk cost fallacy.

Também é possível encontrar o conceito do efeito do custo perdido como a denominação de falácia do jogador (ou Gambler's fallacy).

Moon e Keasey (1999), Parayre (1994) Zeelenberg e Dijk (1997) e Arkes e Blumer (1985 apud YATES \& TAN, 1995), entre outros, demonstram que, ao contrário do que diz a teoria econômica clássica, o efeito do custo perdido é observado no comportamento dos indivíduos.

O efeito do custo perdido foi notado também por Friedman et al (2004) por meio de um jogo de computador em que os participantes enfrentam uma situação de custo perdido ao mover de uma ilha para outra. Entretanto, esses autores notaram que o efeito era pequeno e errático, ao contrário do que diz a literatura. Barham, Chavas e Coomes (1998) 
mostram a questão dos custos perdidos para a indústria de extração da borracha. Reinhardt (1973) usa o conceito ao descrever o fracasso do projeto Tri Star L-1011 da empresa Lockheed. Drummond $(1998,1999)$ apresenta o caso do projeto Taurus, iniciativa da bolsa de valores de Londres, no início da década de 90.

Arkes e Ayton (1999) chamam a atenção de que o efeito do custo perdido tem sido estudado nas áreas das ciências da vida com o nome de efeito Concorde. Esse nome é derivado do célebre avião construído pela França e pela Grã-Bretanha, que representou um projeto inviável para ambos os países. Esse nome tem sido usado para a presença de situação similar do efeito do custo perdido, só que em animais.

0 efeito do custo perdido pode ser influenciado por diversas variáveis. Uma delas é o valor monetário envolvido. Essa situação foi apresentada por Arkes e Blumer (apud ARKES \& AYTON, 1999) e se refere ao experimento em que três tipos de ingressos são vendidos para a temporada do Ohio University Theater. 0 primeiro grupo comprou ingresso pelo preço completo, de \$15; outro grupo pelo preço de \$13; e o último grupo pelo preço de $\$ 8$. Aqueles que compraram ingresso pelo menor preço tiveram uma freqüência menor nos meses subseqüentes. Aparentemente, aqueles que tinham "perdido" uma maior quantidade de dinheiro estavam mais motivados a usar os ingressos.

Arkes e Ayton (1999) também chamam a atenção para o fato de que adultos estão mais sujeitos ao efeito do custo perdido. Citando outros estudos, esses autores mostram que crianças são menos susceptíveis a situações como a apresentada pelo estudo clássico de Tversky e Kahneman (1981) da perda do tíquete e da perda do dinheiro.

Este trabalho tem por objetivo estudar se a informação do valor investido num determinado projeto tem influencia sobre o efeito do custo perdido. A questão da pesquisa é: a informação divulgada do valor investido num determinado projeto exerce impacto sobre o efeito do custo perdido?

Neste estudo admite-se como hipótese nula que a proporção das amostras $\left(\mathrm{p}_{\mathrm{o}}\right)$ não se altera com a evidenciação $\left(p_{e}\right)$ ou não do valor do investimento anterior, e a hipótese alternativa é que a proporção das amostras se altera com a evidenciação do investimento anterior:

$$
\begin{aligned}
& H_{0}: p o=p_{e} \\
& H_{1}: p o \neq p_{e}
\end{aligned}
$$

A hipótese nula será rejeitada se houver evidência estatística que a informação do valor do investimento passado interfere na tomada de decisão fazendo com que as freqüências das respostas se alterem substancialmente.

Este texto está dividido em cinco seções. Inicialmente tem-se a introdução. Após, é apresentado o referencial teórico do tema, que envolve a discussão da racionalidade e o efeito do custo perdido. A terceira parte apresenta a metodologia. A seguir são analisados os dados obtidos e o texto é finalizado pelas considerações finais. 


\section{RACIONALIDADE LIMITADA}

A Moderna Teoria de Finanças, que está baseada nas premissas da Hipótese de Eficiência de Mercado (EMH), considera que os tomadores de decisão são racionais e buscam maximizar suas utilidades (POMPIAN, 2006).

A questão da existência ou não de racionalidade dos gestores tem sido objeto de controvérsia e discussão na literatura. Segundo Tversky e Kahneman (1981) para que uma escolha seja racional, ela tem que ser consistente e coerente. No entanto, devido a imperfeições da percepção humana, a mudança de perspectiva pode reverter uma decisão, o que viola as premissas da racionalidade.

Segundo Barberis e Thaler (2001), em finanças, a racionalidade tem dois significados. 0 primeiro significado baseia-se em que as crenças dos agentes de mercado são corretas, pois a subjetividade usada para diagnosticar os efeitos futuros das variáveis não conhecidas está de acordo com as realizações observadas previamente. 0 segundo, é que dadas suas crenças, os agentes fazem escolhas que são normalmente aceitáveis no sentido que são consistentes com sua utilidade esperada.

Apesar da grande importância da Moderna Teoria de Finanças, as Finanças Comportamentais surgem para melhor explicar fenômenos financeiros utilizando modelos nos quais os agentes não são totalmente racionais por utilizarem heurísticas que conduzem a vieses em seu comportamento que impactam na tomada de decisão (BARBERIS \& THALER, 2001).

As pesquisas realizadas na área de finanças comportamentais constataram a existência de diferentes tipos de vieses no processo de tomada de decisão. Entre esses, é interessante destacar, em razão do tema desse artigo, o excesso de confiança e a heurística da representatividade.

O excesso de confiança é um viés observado quando os tomadores de decisão superestimam o grau de acerto de suas estimativas iniciais quando tomam decisões de negócios (MCMAHON, 2006). Barberis e Thaler (2001) explicam esse viés nas situações práticas nas quais as pessoas acham que um evento é certo quando ocorrem em somente $80 \%$ das vezes e julgam algo como impossível de ocorrer para aqueles eventos que aparecem em $20 \%$ das vezes. Nas situações em que existe o excesso de confiança, as pessoas tratam as premissas como um fato, deixando de considerar as incertezas existentes no cenário. Em tais situações, acabam por assumir, de forma errada, que uma decisão ou evento não possui risco (MCMAHON, 2006). Com o excesso de confiança, a pessoa superestima a probabilidade de um resultado favorável e subestima a probabilidade de ocorrência de um resultado negativo. Em tais casos, os indivíduos acreditam ter um forte censo de controle dos eventos (MCMAHON, 2006). Uma situação conhecida na área de finanças comportamentais, no que diz respeito ao excesso de confiança, ocorre quando se pergunta para as pessoas se são bons motoristas, e uma percentagem elevada, muito acima de $50 \%$, responde afirmativamente. Diversas situações nas quais ocorre o efeito do custo perdido existem quando o tomador de decisão tem excesso de confiança.

Outro erro de percepção importante é a representatividade. Esse problema ocorre quando se faz generalizações sobre um evento ou uma pessoa baseada em poucas observações de um evento similar e poucas informações sobre a pessoa. Em outras palavras, os julgamentos são baseados em estereótipos formados a partir de evidências passadas (MCMAHON, 2006). A representatividade é uma forma de atalho mental, mas sua existência causa um viés na percepção dos indivíduos, que é a negligência do tamanho da amostra. As pessoas não consideram que as observações disponíveis representam somente uma pequena parcela das situações disponíveis e generalizam suas conclusões a partir de 
poucas observações. Outra forma de explicar a questão da representatividade é afirmar que nessas situações as pessoas julgam que uma amostra pequena é tão representativa quanto uma grande. Barberis e Thaler (2001) citam o exemplo de um analista financeiro que é considerado bom por ter acertado quatro estimativas referente ao preço de uma determinada ação. Entretanto, o acerto de quatro ações diz respeito a um número pequeno de observações, quando se considera o mercado como um todo.

McMahon (2006) afirma que o problema da representatividade causa outro viés, o da negligência da taxa base. Nesse viés os tomadores de decisão ignoram informações associadas às situações passadas similares, tendendo a focar sua análise em informações de um passado recente, desconsiderando o longo prazo.

Especificamente, a respeito do efeito do custo perdido, quando uma decisão de projeto futuro é afetada por um investimento feito no passado é denominado de efeito do custo perdido (YATES \& TAN, 1995). Esse efeito ocorre porque os indivíduos têm a esperança de recuperá-lo no futuro, vislumbram que uma decisão futura salvará o investimento feito no passado; no entanto, custos perdidos são totalmente irrelevantes para decisão sobre eventos futuros.

Apenas os custos que alteram nos cenários propostos devem interessar; caso o valor do custo permaneça inalterado, independente da alternativa a ser escolhida, então o valor do custo deve ser ignorado. Essa afirmação está de acordo com a teoria econômica clássica e com a própria contabilidade de custos, na qual apenas os custos e benefícios incrementais devem afetar as decisões sobre eventos futuros. Baseado nessa impossibilidade de ação sobre o custo perdido, afirma-se sua irrelevância para ações presentes e futuras.

Mas segundo Parayre (1995) os indivíduos tendem a lançar "good money after bad", pois são tomados pela angústia ao abandonar um investimento antes que este possa trazer retorno positivo. Ainda segundo Parayre (1995), se o objetivo é maximizar o lucro, então a alocação de recursos em algum ponto no tempo deve ser baseada exclusivamente em custos e benefícios futuros, não em custos passados. Os valores investidos no passado são custos perdidos, que não podem ser alterados ou recuperados com decisões futuras. Entretanto, a tentação de incluir os custos perdidos em análise de cenários de projeto futuro é forte (GARRISON \& NOREEN, 2001).

\section{METODOLOGIA}

A pesquisa foi realizada numa grande universidade brasileira, no mês de julho de 2006, e os questionários foram aplicados a cento e setenta e seis alunos de graduação dos cursos de ciências contábeis, administração, economia e estatística. Como tem ocorrido em algumas pesquisas experimentais de finanças comportamentais (vide, por exemplo, LIMA, 2007 e DOMINGOS, 2007), utilizou-se mais de um questionário. Cada aluno respondeu a somente um único questionário. Os respondentes foram selecionados de acordo com a conveniência, uma vez que o instrumento de pesquisa foi aplicado em salas de aula. Foram dadas instruções quanto ao preenchimento do questionário sem especificar o assunto da pesquisa para não influenciar as respostas. Por ser um questionário pequeno, o tempo médio de resposta foi de 5 minutos.

Cada questionário foi elaborado com uma questão fechada e três abertas, nas quais seria possível, caso necessário, justificar a resposta. Além das questões, o respondente informou o curso e o semestre. Com as justificativas das escolhas, espera-se saber se existia algum conhecimento prévio do conceito de custo perdido, principalmente pelos 
alunos de contábeis. A escolha do grupo de alunos que participou do experimento foi aleatória, assim como a entrega dos questionários.

Os instrumentos de pesquisa utilizados são adaptações de Arkes e Blumer (1985 apud YATES \& TAN, 1999). Foram preparados dois problemas com dois cenários cada, o que equivale dizer que foram utilizados quatro tipos de questionários e, cada aluno respondeu a somente um questionário. Para cada um dos problemas, havia um cenário contendo o valor do investimento anterior, e outro sem a informação do valor do investimento anterior.

Do total de alunos, noventa responderam os questionários com os cenários 1-A e 1-B do problema 1 e oitenta e seis responderam os questionários com os cenários 2-A e 2-B do problema 2.

No primeiro problema, apresentado a seguir, denominado de problema 1, foi realizada uma pergunta sobre uma possível viagem de final de semana para dois diferentes festivais de cinema. Os respondentes deveriam indicar em qual festival iriam.

\section{Problema: 1-A - Sem investimento anterior}

"Suponha que você tenha comprado um bilhete de passagem para passar um final de semana no festival de cinema em Gramado. Algumas semanas mais tarde você compra um bilhete de passagem para o festival de cinema em Parati. Você imagina que o festival de cinema em Parati será muito melhor que o festival em Gramado. Dias mais tarde, você percebe que os dois festivais acontecerão no mesmo final de semana, percebe que é muito tarde para vender qualquer um dos bilhetes e que não pode devolver qualquer um deles. Você deve usar um dos bilhetes e o outro não. Para qual dos festivais você iria?"

Para testar o efeito da informação do investimento, o questionário espelho apresentava o mesmo problema com pequenas diferenças decorrentes da necessidade de apresentar valores:

\section{Problema: 1-B - Com investimento anterior em Reais}

"Suponha que você tenha comprado um bilhete de passagem por $R \$$ 1.000,00 para passar um final de semana no festival de cinema em Gramado. Algumas semanas mais tarde você compra um bilhete de passagem por $R \$ 500,00$, para o festival de cinema em Parati. Você imagina que o festival de cinema em Parati será muito melhor que o festival em Gramado. Dias mais tarde, você percebe que os dois festivais acontecerão no mesmo final de semana, percebe que é muito tarde para vender qualquer um dos bilhetes e que não pode devolver qualquer um deles. Você deve usar um dos bilhetes e o outro não. Para qual dos festivais você iria?

Um segundo problema explicita uma situação menos pessoal. Refere-se a um projeto de pesquisa para construção de um automóvel que utiliza combustível alternativo, mas ressalva que o concorrente inicia a propaganda de um automóvel também movido a 
óleo de mamona, porém, mais econômico e veloz que o da sua empresa. Diante desta situação, foi solicitado aos respondentes que indicassem se concluiriam ou não o projeto da sua empresa. Essa também é uma situação de custo perdido em que é apresentado o valor total do projeto e o valor que falta:

Problema: 2-A - Com investimento anterior em Reais

"Suponha que você seja o diretor presidente de uma empresa automobilística que tenha investido num projeto de pesquisa de 9 milhões para construção de um veículo movido a óleo de mamona, e que falta 1 milhão para concretizá-lo. Nesse ponto, outra empresa inicia a propaganda de um veículo moderno movido a óleo de mamona e que é muito mais econômico e veloz que o da sua empresa. Você investiria o restante necessário para finalizar o projeto de pesquisa da sua empresa?"

O questionário espelho mostra a mesma situação, somente com o valor faltante.

\section{Problema: 2-B - Sem investimento anterior}

"Suponha que você seja o diretor presidente de uma empresa automobilística que tenha investido num projeto de pesquisa para construção de um veículo movido a óleo de mamona, e que falta 1 milhão para concretizá-lo. Nesse ponto, outra empresa inicia a propaganda de um veículo moderno movido a óleo de mamona e que é muito mais econômico e veloz que o da sua empresa. Você investiria o restante necessário para finalizar o projeto de pesquisa da sua empresa?"

Para verificar se a resposta está de acordo ou não com as hipóteses a serem testadas, utilizou-se o teste do qui-quadrado $\left(\chi^{2}\right)$. Esse modelo não paramétrico tem como característica não exigir que a amostra seja distribuída normalmente, ou seja, é livre de distribuição. A escolha do $\chi^{2}$ deve-se ao fato de os dados desta pesquisa apresentarem-se sob forma de freqüências em categorias discretas. Com o teste do $\chi^{2}$ pretende-se testar a significância da diferença entre as respostas dos alunos aos diferentes cenários trabalhados, reforçando, assim, a idéia de que o efeito do custo perdido na decisão de alocação de recursos é independente da evidenciação ou não dos valores investidos.

\section{ANÁLISE DOS DADOS}

A Tabela 1 mostra as respostas dos alunos para o problema do festival (problema 1), no qual o estudo da existência ou não do efeito do custo perdido ocorreria numa situação de decisão pessoal. No problema, o respondente deveria escolher entre uma viagem a Gramado, uma vez que, foram gastos 1.000 reais com a compra da passagem, contra 500 reais gastos para ir à Parati. Com relação aos dados apresentados na tabela, observa-se que $64 \%$ dos respondentes ao cenário no qual não foram apresentados os valores gastos, 
escolheram ir ao festival de Parati por haver uma expectativa de que a viagem seja a mais divertida dentre as opções.

Tabela 1: Freqüências (percentuais) das seleções para o festival.

\begin{tabular}{lccc}
\multicolumn{1}{c}{ Escolha } & $\begin{array}{c}\text { Com investimento } \\
\text { anterior }\end{array}$ & $\begin{array}{c}\text { Sem investimento } \\
\text { anterior }\end{array}$ & Total \\
\hline Festival de Parati & $27(60 \%)$ & $29(64 \%)$ & $56(62 \%)$ \\
\hline Festival de Gramado & $18(40 \%)$ & $16(36 \%)$ & $34(38 \%)$ \\
\hline Total & $45(100 \%)$ & $45(100 \%)$ & $90(100 \%)$
\end{tabular}

O resultado do cenário em que se fez a evidenciação dos valores já gastos apresentou que também a maioria dos respondentes (60\%) escolheu o festival de Parati pelo mesmo motivo que os demais. Para este problema, observa-se que não ficou caracterizado um forte efeito do custo perdido, pois somente, aproximadamente, $40 \%$ dos respondentes escolheram o festival de Gramado em detrimento ao de Parati.

É importante ressaltar que a evidenciação ou não do valor do investimento prévio não altera o resultado, pois com o teste do $\chi^{2}$ apresentou um resultado de $0,047(1, N=$ 90). Desse modo, quando se considera um nível de significância de $0,01, \mathrm{H}_{0}$ não foi rejeitada, o que significa dizer que a diferença apresentada nos resultados dos dois cenários se deu devido ao acaso. Entretanto, essa afirmação deve ser considerada com ressalva, uma vez que o valor do teste estaria abaixo do nível de 0,05, que também é usado em situações análogas.

Procurou-se verificar se os resultados apurados foram influenciados pela maturidade do estudante. Para isso, os respondentes foram agrupados de acordo com a posição do aluno no curso. Considerou-se que a fase inicial do curso seria do $1^{\circ}$ ao $3^{\circ}$ semestre; a fase intermediária, do $4^{\circ}$ ao $6^{\circ}$ semestre; e a fase final, do $7^{\circ}$ ao $11^{\circ}$ semestre.

$\mathrm{Na}$ fase inicial do curso, $1^{\circ}$ ao $3^{\circ}$ semestre, foi observado que, para o contexto pessoal, $68 \%$ dos participantes que sabiam a quantia de dinheiro já investido preferiram ir para o festival de Parati, por ser mais divertido. E no cenário em que o valor do investimento prévio não foi evidenciado, quase que a totalidade da amostra (92\%) escolheu viajar para Parati, conforme tabela 2. Pode-se concluir que para o grupo inicial, o efeito do custo perdido não foi evidenciado. 0 teste do $\chi^{2}$ apresentou um valor de 2,697, o que para um nível de significância de 0,01 não se rejeita $H_{0}$. Logo, a evidenciação da informação do montante de recurso já investido não é relevante para este contexto.

Já do $4^{\circ}$ ao $6^{\circ}$ semestre, o fato de não evidenciar o valor do investimento anterior fez com que os respondentes apresentassem o efeito do custo perdido, pois $57 \%$ dos participantes escolheram viajar para Gramado. Mas, com a evidenciação dos valores previamente investidos, o efeito do custo perdido não foi observado, uma vez que somente 29\% dos respondentes escolheram o Festival de Gramado. Para um nível de significância de 0,01 , o $\chi^{2}$ foi de 2,76 , com valor crítico de 6,635. Isso significa afirmar que essas diferenças não são significativas.

Com relação ao grupo do $7^{\circ}$ ao $11^{\circ}$ semestre, $78 \%$ dos alunos escolheram participar do Festival de Gramado quando o investimento foi evidenciado. Quando não houve a evidenciação do investimento prévio somente $27 \%$ dos participantes viajariam para 
Gramado. Dessa forma, fica evidenciado que os alunos, na fase final de seus cursos, foram sensíveis ao cenário exposto, isto é, foi observado o efeito do custo perdido somente quando o valor do investimento foi informado. Mas de acordo com o teste realizado para este cenário $\left(\chi^{2}=5,501\right.$, com 0,01 grau de significância), essa sensibilidade ao cenário não é significativa, ou seja, as diferenças nas proporções das respostas se deram devido à amostragem ou ao acaso.

Tabela 2: Freqüências (percentuais) das seleções para o festival por semestre.

\begin{tabular}{lcccccc}
\hline & \multicolumn{2}{c}{ Semestre } \\
\cline { 2 - 7 } & \multicolumn{2}{c}{$\mathbf{1}^{\circ}$ ao $\mathbf{3}^{\circ}$} & \multicolumn{2}{c}{$\mathbf{4}^{\circ}$ ao $\mathbf{6}^{\circ}$} & \multicolumn{2}{c}{$\mathbf{7}^{\circ}$ ao $\mathbf{1 1}^{\circ}$} \\
\hline Escolha & $\begin{array}{c}\text { Com } \\
\text { investimento } \\
\text { anterior }\end{array}$ & $\begin{array}{c}\text { Sem } \\
\text { investimento } \\
\text { anterior }\end{array}$ & $\begin{array}{c}\text { Com } \\
\text { investimento } \\
\text { anterior }\end{array}$ & $\begin{array}{c}\text { Sem } \\
\text { investimento } \\
\text { anterior }\end{array}$ & $\begin{array}{c}\text { Com } \\
\text { investimento } \\
\text { anterior }\end{array}$ & $\begin{array}{c}\text { Sem } \\
\text { investimento } \\
\text { anterior }\end{array}$ \\
\hline $\begin{array}{l}\text { Festival } \\
\text { Parati }\end{array}$ & $15(68 \%)$ & $12(92 \%)$ & $10(71 \%)$ & $9(43 \%)$ & $2(22 \%)$ & $8(73 \%)$ \\
\hline $\begin{array}{l}\text { Festival } \\
\text { Gramado }\end{array}$ & $7(32 \%)$ & $1(8 \%)$ & $4(29 \%)$ & $12(57 \%)$ & $7(78 \%)$ & $3(27 \%)$ \\
\hline Total & 22 & 13 & 14 & 21 & 9 & 11
\end{tabular}

A Tabela 3 mostra os resultados do problema 2, que trata de um projeto da construção de um veículo movido a combustível alternativo. Conforme afirmado anteriormente, essa questão não é pessoal. Observa-se uma forte incidência do efeito do custo perdido para os dois cenários, pois cerca de $80 \%$ dos respondentes optaram por concluir o projeto na tentativa de recuperar o recurso investido anteriormente. Vale ressaltar que também neste caso, a evidenciação do valor já investido não interfere na decisão de continuar ou não o projeto, ou seja, $\mathrm{H}_{0}$ não foi rejeitada no teste do $\chi^{2}$ cujo valor foi de 0,011 $(1, \mathrm{~N}=86)$ para 0,01 nível de segurança.

Tabela 3: Freqüências (percentuais) das seleções para a conclusão do projeto.

\begin{tabular}{lccc}
\multicolumn{1}{c}{ Escolha } & $\begin{array}{c}\text { Com investimento } \\
\text { anterior }\end{array}$ & $\begin{array}{c}\text { Sem investimento } \\
\text { anterior }\end{array}$ & Total \\
\hline Concluir o projeto & $35(80 \%)$ & $34(81 \%)$ & $69(80 \%)$ \\
\hline Não concluir o projeto & $9(20 \%)$ & $8(19 \%)$ & $17(20 \%)$ \\
\hline Total & $44(100 \%)$ & $42(100 \%)$ & $86(100 \%)$
\end{tabular}

No contexto menos pessoal, no qual a decisão em questão é a de concluir ou não o projeto de um automóvel movido a óleo de mamona, em todas as classificações dos semestres, conforme tabela 4, o efeito do custo perdido foi observado, tanto para o cenário em que a informação do valor do investimento foi apresentada, quanto para o que tal informação não foi evidenciada. Para a primeira $\left(1^{\circ}\right.$ ao $3^{\circ}$ semestre $)$ e segunda $\left(4^{\circ}\right.$ ao $6^{\circ}$ semestre) fases do curso, a classificação a hipótese nula não foi rejeitada para um nível de significância de 0,01 , com $\chi^{2}=0,013$ e 5,565. Logo, as variações percebidas são atribuídas ao acaso. 
Tabela 4: Freqüências das seleções para a conclusão do projeto por semestre.

\begin{tabular}{lcccccc} 
& \multicolumn{1}{c}{ Semestre } \\
\cline { 2 - 7 } & \multicolumn{2}{c}{$\mathbf{1}^{\circ}$ ao $\mathbf{3}^{\circ}$} & \multicolumn{2}{c}{$\mathbf{4}^{\circ}$ ao $\mathbf{6}^{\circ}$} & \multicolumn{2}{c}{$\mathbf{7}^{\circ}$ ao $\mathbf{1 1}^{\circ}$} \\
\hline Escolha & $\begin{array}{c}\text { Com } \\
\text { investimento } \\
\text { anterior }\end{array}$ & $\begin{array}{c}\text { Sem } \\
\text { investimento } \\
\text { anterior }\end{array}$ & $\begin{array}{c}\text { Com } \\
\text { investimento } \\
\text { anterior }\end{array}$ & $\begin{array}{c}\text { Sem } \\
\text { investimento } \\
\text { anterior }\end{array}$ & $\begin{array}{c}\text { Com } \\
\text { investimento } \\
\text { anterior }\end{array}$ & $\begin{array}{c}\text { Sem } \\
\text { investimento } \\
\text { anterior }\end{array}$ \\
\hline $\begin{array}{l}\text { Conclui o } \\
\text { projeto }\end{array}$ & $11(69 \%)$ & $12(71 \%)$ & $22(85 \%)$ & $16(84 \%)$ & $2(100 \%)$ & $6(100 \%)$ \\
\hline $\begin{array}{l}\text { Não } \\
\text { conclui o } \\
\text { projeto }\end{array}$ & $5(31 \%)$ & $5(29 \%)$ & $4(15 \%)$ & $3(16 \%)$ & 0 & 0 \\
\hline Total & 16 & 17 & 26 & 19 & 2 & 6 \\
\hline
\end{tabular}

Ao segregar a amostra em grupos caracterizados pela área de conhecimento, em estudantes do curso de ciências contábeis contra os demais cursos, não é observada a incidência do efeito do custo perdido, conforme evidenciado na tabela 5 . Em todos os casos, mais de $50 \%$ dos entrevistados escolheram ir para Parati que, embora seja uma viagem mais barata, pode ser mais divertida. Ao realizar teste estatístico $\left(\chi^{2}=1,725\right.$ para 0,01 de significância), observa-se que o curso não interfere na escolha, ou seja, não há diferença significativa entre as respostas dos contadores e não contadores.

Tabela 5: Freqüência (percentual) das seleções dos alunos de contabilidade e de outros cursos.

\begin{tabular}{|c|c|c|c|c|c|c|}
\hline \multirow[b]{2}{*}{ Escolha } & \multicolumn{3}{|c|}{ Contabilidade } & \multicolumn{3}{|c|}{ Outros cursos } \\
\hline & $\begin{array}{l}\text { Com } \\
\text { investimento } \\
\text { anterior }\end{array}$ & $\begin{array}{c}\text { Sem } \\
\text { investimento } \\
\text { anterior }\end{array}$ & Total & $\begin{array}{c}\text { Com } \\
\text { investimento } \\
\text { anterior }\end{array}$ & $\begin{array}{c}\text { Sem } \\
\text { investimento } \\
\text { anterior }\end{array}$ & Total \\
\hline Festival de Parati & $6(55 \%)$ & 13 (76\%) & 19 & $21(62 \%)$ & $16(57 \%)$ & 37 \\
\hline $\begin{array}{l}\text { Festival de } \\
\text { Gramado }\end{array}$ & $5(45 \%)$ & $4(24 \%)$ & 9 & $13(38 \%)$ & $12(43 \%)$ & 25 \\
\hline Total & 11 & 17 & 28 & 34 & 28 & 62 \\
\hline
\end{tabular}

Com relação ao projeto de investimento (Tabela 6), os dados apresentam um forte efeito do custo perdido tanto para os contadores quanto para os não contadores. De forma análoga aos resultados anteriores, a variável curso não é significativa para o efeito do custo perdido, pois $H_{0}$ não foi rejeitada $\left(\chi^{2}=0,719\right.$, para nível de significância de 0,01$)$.

Tabela 6: Freqüência (percentual) das seleções dos alunos de contabilidade e de outros cursos.

\begin{tabular}{|c|c|c|c|c|c|c|}
\hline \multirow[b]{2}{*}{ Escolha } & \multicolumn{3}{|c|}{ Contabilidade } & \multicolumn{3}{|c|}{ Outros cursos } \\
\hline & $\begin{array}{c}\text { Com } \\
\text { investimento } \\
\text { anterior }\end{array}$ & $\begin{array}{c}\text { Sem } \\
\text { investimento } \\
\text { anterior }\end{array}$ & Total & $\begin{array}{c}\text { Com } \\
\text { investimento } \\
\text { anterior }\end{array}$ & $\begin{array}{c}\text { Sem } \\
\text { investimento } \\
\text { anterior }\end{array}$ & Total \\
\hline Conclui o projeto & 14 (78\%) & 14 (88\%) & 28 & $21(81 \%)$ & 20 (77\%) & 41 \\
\hline $\begin{array}{l}\text { Não conclui o } \\
\text { projeto }\end{array}$ & $4(22 \%)$ & $2(12 \%)$ & 6 & $5(19 \%)$ & $6(23 \%)$ & 11 \\
\hline Total & 18 & 16 & 34 & 26 & 26 & 52 \\
\hline
\end{tabular}

Fonte: Própria 
Assim, corroborando com o estudo realizado por Yates e Tan (1999), os resultados desta pesquisa mostram que o efeito do custo perdido sobre o tomador de decisão depende de como o contexto é apresentado. No entanto, isso independe da evidenciação do valor já investido. Neste estudo, os tomadores de decisão foram confrontados com questões cotidianas, de cunho pessoal (problema 1), com valores investidos relativamente pequenos. Também foram confrontados com questões relacionadas às decisões de investimento volumoso, semelhante às que administradores de recursos de terceiros se deparam no dia a dia das empresas (problema 2).

Observou-se que, para as decisões de cunho pessoal, os tomadores de decisão tendem a apresentar um menor efeito do custo perdido, enquanto que na presença de decisões relacionadas a investimento de negócio, existe uma forte presença do efeito do custo perdido na tentativa de resgatar o montante já investido. 0 que corrobora, também, o estudo realizado por Yates e Tan (1999), pois o indivíduo preocupa-se em não apresentar desperdício de recurso, não apenas para si mesmo, mas também diante de outras pessoas, principalmente, quando elas podem puni-lo pelo evento desastroso.

\section{CONSIDERAÇÕES FINAIS}

Sob o prisma do efeito do custo perdido, esta pesquisa buscou identificar se a evidenciação do valor investido anteriormente afeta ou não as decisões de alocação de recursos. Também procurou verificar se o conhecimento acadêmico, medido pela posição do aluno no semestre do curso, afeta a decisão. A análise foi feita com base nas cento e setenta e seis observações coletadas por meio de aplicação de questionários, de forma aleatória, aos alunos de graduação de uma grande universidade.

Apesar de a amostra ser composta por alunos de graduação e isso representar uma limitação para as conclusões do trabalho, é importante destacar que diversos casos relatados na realidade mostram que o efeito do custo perdido também ocorre em situações reais (vide, por exemplo, DOMINGOS, 2007). De qualquer forma, replicar essa pesquisa para gestores que efetivamente tomam decisões de investimento pode ser uma interessante expansão desse trabalho. De qualquer forma, algumas pesquisas demonstraram que a presença de responsabilidade pessoal tende a aumentar a incidência do efeito do custo perdido, como é o caso do estudo de White (1993) e Conlon e Parks (1987).

De acordo com os resultados apresentados na pesquisa, verifica-se que a evidenciação do valor do custo perdido não influencia a tomada de decisão. Ao testar os agrupamentos da amostra em alunos do curso de ciências contábeis e demais cursos foi observado que essa condição não é significativa no processo de tomada de decisão. Entretanto, é importante salientar que, de acordo com os dados, o cenário, o contexto do custo, influencia na incidência ou não do custo perdido. Para o cenário no qual foi testada uma decisão relacionada ao cotidiano das pessoas, não houve a ocorrência do custo perdido, talvez pela pequena importância do valor apresentado. Entretanto, ao defrontarse com um cenário em que a decisão envolve negócios, o tomador de decisão se torna mais propenso a apresentar o efeito do custo perdido. 0 resultado corrobora estudos anteriores nos quais o efeito custo perdido foi verificado.

Sugere-se que esta pesquisa seja replicada com um número maior de participantes, e que o questionário traga, além dos problemas e cenários, questões como sexo, idade, experiência profissional e se as disciplinas que tratam do conceito já foram cursadas, para que possa haver uma maior generalização dos resultados. 


\section{REFERÊNCIAS}

ARKES, Hal; AYTON, Peter. The Sunk Cost an Concorde Effects: Are Humans Less Rational Than Lower Animals? Psychological Bullettin, v. 125, 5, p. 591- 600, 1999.

BARBERIS, Nicholas; THALER, Richard. A Survey of Behavioral Finance. University of Chicago. Working paper, 2001.

BARHAM, B. L.; CHAVAS, J. P.; COOMES, O. T. Sunk costs and the natural resource extraction sector. Land Economics. v. 74, 4, p. 429 - 448, 1998.

CONLON, E. J.; PARKS, J. M. Information requests in the context of escalation. Journal of Applied Pscychology. v. 72, 3, p. 344-350, 1987.

DRUMMOND, $\mathrm{H}$. Are we any closer to the end? International Journal of Project Management. v. 17, 1, p. 11-16, 1999.

DRUMMOND, H. Riding a tiger: some lessons of Taurus. Management Decision. v. 36, n. 3 , p. 141-146, 1998.

DOMINGOS, Naiára. Custos perdidos e insistência irracional. Brasília, 2007. Dissertação (Mestrado em Ciências Contábeis). Universidade de Brasília. Brasília, 2007.

FRIEDMAN, Daniel et al. Searching for the Sunk Cost Fallacy. Ideas Repec, Connecticut, 2004. .Acesso em: 15 mar. 2007.

GARRISON, Ray H. NOREEN, Eric W. Contabilidade Gerencial. Rio de Janeiro: LTC, 2001.

LIMA, Diogo H. FORMULAÇÃO E CONTABILIDADE: UMA ANÁLISE DA INFLUÊNCIA DA FORMA DE APRESENTAÇÃO DE DEMONSTRATIVOS E RELATÓRIOS CONTÁBEIS SOBRE O PROCESSO DECISÓRIO DE USUÁRIOS DE INFORMAÇÕES CONTÁBEIS Natal, 2007. Dissertação (Mestrado em Ciências Contábeis ). Universidade Federal do Rio Grande do Norte, Natal, 2007.

MARTINS, Eliseu. Contabilidade de custos. São Paulo: Atlas, 2001.

MCMAHON, Richard G.P. Behavioural Finance: A Backround Briefing. School of Commerce Research Paper Series working paper, 2006.

MOON, P.; KEASEY, K. A test of the importance of context. Economics Letters. v. 66, p. 55-58, 1999.

PARAYRE, R. The strategic implications of sunk costs: A behavioral perspective. Journal of economics behavior and organization. v.28, p. 417- 422, 1995.

POMPIAN, Michael M. Behavioral Finance and Wealth Management: How to Build Optmal Portfolios That Account for Investor Biases. New Jersey: Wiley. 2006.

RABIN, Matthew. Psychology and Economics. Journal of Economic Literature. v. 36, p. 1146, 1998.

REINHARDT, U. E. Break-even analysis for Lockheed's Tri Star. The Journal of Finance. v. 28, 4, p. 821-838, 1973.

SIEGEL, Sidney. Estatística Não-Paramétrica para as Ciências do Comportamento. Trad. Alfredo Alves Farias. São Paulo: McGraw-Hill, 1979.

SLOVIC, Paul; FISCHHOFF, Baruch; LICHTENSTEIN, Sarah. Behavioral Decision Theory. Annual Review Psychology. v. 28, p. 1-31, 1977.

TVERSKY, Amos; KAHNEMAN, Daniel. The Framing of Decisions and the Psychology of Choice. Science, v. 211, p. 453-458, 1981. 
WHITE, G. Escalating commitment in individual and group decision making. Organizational Behavior and Human Decision Processes. v. 54, 3, p. 430-455, 1993.

YATES, J. Frank; TAN, Hun-Tong. Sunk Cost Effects: The Influence of instruction and Future Return Estimates. Organizational Behavior and Human Decision Processes. v. 63, 3, p. 311-319, 1995.

ZEELENBERG, M.; DIJK E. A reverse sunk cost effect in risky decision making: sometimes we have too much invested to gamble. Journal of economics psychology. v.18, p. 677-691, 1997.

\section{ENDEREÇO DOS AUTORES}

Universidade de Brasília

Departamento de Ciências Contábeis e Atuariais

Campus Darcy Ribeiro - Asa Norte

Predio da FAD - Sala B102

Brasília, DF - Brasil

70910-900
Universidade de Brasília

Reitoria - Secretaria de Planejamento

Campus Darcy Ribeiro - Plano Piloto

Brasilia, DF - Brasil

70910-900

Secretaria de Estado de Planejamento e Gestão

Anexo do Palácio do Buriti, Sala 1010

Asa Norte

Brasilia, DF - Brasil

72000-000 